\title{
Characterization of Milkisin, a Novel Lipopeptide With Antimicrobial Properties Produced By Pseudomonas sp. UCMA 17988 Isolated From Bovine Raw Milk
}

\author{
Margot Schlusselhuber ${ }^{1 *}$, Justine Godard ${ }^{1}$, Muriel Sebban ${ }^{2}$, Benoit Bernay ${ }^{3}$, \\ David Garon', Virginie Seguin', Hassan Oulyadi ${ }^{2}$ and Nathalie Desmasures ${ }^{1}$ \\ 1 UNICAEN, UNIROUEN, ABTE, Normandie Université, Caen, France, ${ }^{2}$ UNIROUEN, INSA Rouen, CNRS, COBRA, \\ Normandie Université, Rouen, France, ${ }^{3}$ UNICAEN, SF ICORE 4206, Normandie Université, Caen, France
}

OPEN ACCESS

Edited by:

Santi M. Mandal,

Indian Institute of Technology

Kharagpur, India

Reviewed by:

Taoufik Ghrairi,

Tunis El Manar University, Tunisia

Suresh Korpole,

Institute of Microbial

Technology (CSIR), India

${ }^{*}$ Correspondence:

Margot Schlusselhuber

margot.schlusselhuber@unicaen.fr

Specialty section:

This article was submitted to Antimicrobials, Resistance

and Chemotherapy,

a section of the journal

Frontiers in Microbiology

Received: 26 January 2018 Accepted: 01 May 2018

Published: 28 May 2018

Citation:

Schlusselhuber M, Godard J, Sebban M, Bernay B, Garon D,

Seguin V, Oulyadi $H$ and Desmasures N (2018)

Characterization of Milkisin, a Novel Lipopeptide With Antimicrobial

Properties Produced By Pseudomonas sp. UCMA 17988 Isolated From Bovine Raw Milk.

Front. Microbiol. 9:1030. doi: 10.3389/fmicb.2018.01030
Biosurfactants such as lipopeptides are amphiphilic compounds produced by microorganisms such as bacteria of the genera of Pseudomonas and Bacillus. Some of these molecules proved to have interesting antimicrobial, antiviral, insecticide and/or tensio-active properties that are potentially useful for the agricultural, chemical, food, and pharmaceutical industries. Raw milk provides a physicochemical environment that is favorable to the multiplication of a broad spectrum of microorganisms. Among them, psychrotrophic bacterial species, especially members of the genus Pseudomonas, are predominant and colonize milk during cold storage and/or processing. We isolated the strain Pseudomonas sp. UCMA 17988 from raw cow milk, with antagonistic activity against Listeria monocytogenes, Staphylococcus aureus, and Salmonella enterica Newport. Antimicrobial molecules involved in the antagonistic activity of this strain were characterized. A mass spectrometry analysis highlighted the presence of four lipopeptides isoforms. The major isoform (1409 m/z), composed of 10 carbons in the lipidic chain, was named milkisin C. The three other isoforms detected at 1381, 1395, and $1423 \mathrm{~m} / \mathrm{z}$, that are concomitantly produced, were named milkisin $\mathrm{A}, \mathrm{B}$ and $\mathrm{D}$, respectively. The structure of milkisin, as confirmed by NMR analyses, is closely related to amphisin family. Indeed, the peptidic chain was composed of 11 amino acids, 9 of which are conserved among the family. In conclusion, Pseudomonas sp. UCMA 17988 produces new members of the amphisin family which are responsible for the antagonistic activity of this strain.

Keywords: antimicrobial activity, Pseudomonas, milkisin, amphisin, lipopeptide

\section{INTRODUCTION}

Biosurfactants are amphiphilic compounds produced by microorganisms such as bacteria, yeasts, and some filamentous fungi (Santos et al., 2016). They contain hydrophobic and hydrophilic groups that confer the ability to accumulate between fluid phases, thereby reducing surface and interfacial tension at the surface and interfacial regions, respectively (Kapadia and Yagnik, 2013). 
Among these molecules, some of them were shown to have interesting antimicrobial, antiviral, insecticide, and/or tensioactive properties that are potentially useful for the agricultural, chemical, food, and pharmaceutical industries (Inès and Dhouha, 2015).

Biosurfactants, such as lipopeptides and glycolipids, are in most cases low-molecular mass membrane-active compounds (usually ranging from 500 to $1500 \mathrm{Da}$ ) (Janek et al., 2010). They are mainly produced by bacteria of the genera Pseudomonas and Bacillus with 70 and 90 different lipopeptides produced, respectively (Santos et al., 2016; Coutte et al., 2017). Recently, a unique online database dedicated to non-ribosomal peptides has been opened (Flissi et al., 2016). 139 lipopeptides produced by Pseudomonas have been recorded and classified into 15 family based on their structures. The better known being amphisin, pyoverdine, viscosin, tolaasin, and syringopeptin groups ${ }^{1}$.

Several isoforms can be produced by one single strain which differs either by the length of the fatty acid chain or by the composition of the peptide moiety. In Pseudomonas and Bacillus genera, most lipopeptides are synthesized in a ribosomeindependent manner with mega enzymes called non-ribosomal peptide synthetases (NRPSs) (Inès and Dhouha, 2015). Those synthetases possess a multimodular structure in which each module is involved in the stepwise incorporation of an amino acid in the lipopeptide peptide moiety. A typical module can be subdivided into initiation and elongation modules. A typical initiation module consists of an adenylation (A) domain, responsible for amino acid selection and activation, a thiolation (T or alternatively PCP) domain responsible for thioesterification of the activated amino acid and a condensation (C) domain. The $\mathrm{C}$ domain of the first module catalyzes $N$-acylation of the first amino acid, thereby linking the lipid moiety to the oligopeptide. Elongation modules contain A, T, and C domains in which the $\mathrm{C}$ domain is responsible for peptide bond formation between two neighboring substrates to elongate the peptide chain. These catalytic domains generate a linear peptide which is cleaved at the end of the assembly line by a thioesterase (TE domain), which results in the release of a linear product or a cyclic compound via an intramolecular cyclization reaction. Additional domains may include an epimerization domain, responsible for the conversion of the L- or D-configuration of an amino acid (Raaijmakers et al., 2010; Roongsawang et al., 2010).

Raw milk provides a physicochemical environment that is favorable to the multiplication of a broad spectrum of microorganisms. Indeed, more than 100 genera and 400 microbial species have been detected in raw milk (Montel et al., 2014). Among them, psychrotrophic bacterial species, especially members of the genus Pseudomonas, are predominant and contaminate milk at different steps from farm to dairies (Mallet et al., 2012), and develop during cold storage and/or processing (De Jonghe et al., 2011). Pseudomonas sp. are aerobic, Gram-negative bacteria and many of them are able to produce heat-stable extracellular enzymes (Herrera, 2000). Because of their ability to produce proteases, able to degrade casein, and

${ }^{1}$ http://bioinfo.lifl.fr/norine/ lipase, causing triglycerides degradation, pseudomonads may cause spoilage in dairy products (Cousin et al., 2001). Within this genus, the $P$. fluorescens group is generally known to frequently cause spoilage of stored milk (Arslan et al., 2011) and of some cheese varieties, although it has also been described on the surface of unspoiled cheese (Larpin-Laborde et al., 2011; Wolfe et al., 2014).

In this work, we aim to describe a novel lipopeptide produced by an isolated strain from bovine raw milk collected in Normandy (France) and identified as Pseudomonas sp. UCMA 17988. This strain produces a novel antibacterial cyclic lipopeptide along with three isoforms supposed to belong to the amphisin family. The structure of the newly discovered biosurfactant, named milkisin, isolated by RP-HPLC, was determined by mass spectrometry (MALDI TOF) and nuclear magnetic resonance (NMR).

\section{MATERIALS AND METHODS}

\section{Isolation and Antibacterial Activity of Pseudomonas sp. UCMA 17988}

Raw bulk tank milk samples collected on farm in Normandy (France) were screened for isolates with antibacterial properties by a double layer agar method. After 10-fold dilution of the samples, $100 \mu \mathrm{l}$ of each dilution was spread over the surface of brain heart infusion (BHI) agar plates supplemented with $0.2 \%$ glucose and incubated overnight at $30^{\circ} \mathrm{C}$. After incubation, $8 \mathrm{ml}$ of BHI soft agar supplemented with $0.2 \%$ glucose was mixed with $1 \%$ (vol/vol) fresh inoculum prepared from overnight culture of bacterial pathogens and overlaid on agar plates containing less than 100 colonies. The bacterial targets used for the screening process were Listeria monocytogenes WSLC 1685, Staphylococcus aureus CIP 53.154, Salmonella enterica serotype Newport CIP 105629, and Escherichia coli O157:H7 stx-C267 (Vernozy-Rozand et al., 2000). The plates were then incubated overnight at $30^{\circ} \mathrm{C}$. Milk isolates with antagonistic activity were detected by observation of a zone of inhibition around the colonies. The antagonistic Pseudomonas sp. UCMA 17988, detected by this method, was picked up with sterile toothpick for purification by isolation using Tryptone Soya Agar - Yeast Extract (TSA-YE) agar plates.

The antagonistic properties of Pseudomonas sp. UCMA 17988 were then studied using the spot-on-lawn technique against selected bacterial strains: L. monocytogenes WSLC 1685, S. aureus CIP 53.154, E. coli O157:H7 stx-C267, and S. enterica serotype Newport CIP 105629, serotype Typhimurium LMG 7233, serotype Dublin CIP 7053, serotype Mbandaka CIP 105859, and serotype Montevideo CIP 104583. To do this, soft BHI agar plates supplemented with $0.2 \%$ glucose were inoculated with target strains. Inoculation was performed with cotton swab dipped into adjusted inoculum $\left(\mathrm{OD}_{600} 0.01\right)$. Excess liquid was removed by gentle rotation of the cotton swab against the inner surface of the test tube. To obtain even growth, the entire agar surface was swabbed uniformly by the cotton swab. The inoculated plates were left at room temperature for 3-5 min to allow any surface moisture to be absorbed. $2.5 \mu \mathrm{l}$ of Pseudomonas sp. UCMA 17988 overnight culture was then spotted prior to 
incubation for $24 \mathrm{~h}$ at $30^{\circ} \mathrm{C}$. Subsequently, the clear zone around the spot was recorded.

\section{PCR Amplification and DNA Sequencing Conditions}

Colony PCR amplification and DNA sequencing of rpoD, and $16 S$ rRNA genes were performed for identification of Pseudomonas sp. UCMA 17988 strain. The $16 S$ rRNA gene sequence was amplified using the primers W18F $\left(5^{\prime}\right.$-GAGTTTGATCMTGGCTCAG-3') and W02R (5'GNTACCTTGTTACGACTT-3') respecting the following PCR conditions: initial hot-start step at $98^{\circ} \mathrm{C}$ for $10 \mathrm{~min}, 35$ cycles of denaturation at $98^{\circ} \mathrm{C}$ for $10 \mathrm{~s}$, annealing at $49.5^{\circ} \mathrm{C}$ for $20 \mathrm{~s}$, and extension at $72^{\circ} \mathrm{C}$ for $45 \mathrm{~s}$; and a final extension of $10 \mathrm{~min}$ at $72^{\circ} \mathrm{C}$. $r p o D$ gene was amplified using the primers set (PsEG30F/PsEG790R), as described by Mulet et al. (2010), respecting the following PCR conditions : $5 \mathrm{~min} 98^{\circ} \mathrm{C}, 30$ cycles $\left(98^{\circ} \mathrm{C} 10 \mathrm{~s}, 55^{\circ} \mathrm{C} 30 \mathrm{~s}, 72^{\circ} \mathrm{C} 25 \mathrm{~s}\right) 5 \mathrm{~min} 72^{\circ} \mathrm{C}$. All PCR reactions were conducted with Thermo Scientific Phusion High-Fidelity PCR Master Mix prior sequencing by GATC Biotech (Cologne, Germany), with Sanger method. Forward and reverse strands were assembled with Bioedit software and deposited to GenBank. The sequence was then compared to the GenBank database (NCBI).

\section{Phylogenetic Analyses}

Phylogenetic analyses were carried out using rpoD and $16 S$ rRNA gene sequences of Pseudomonas sp. UCMA 17988 with type strains obtained from public database (von Neubeck et al., 2017). Alignments were performed by using Muscle Alignment tool (Edgar, 2004) with default settings and were used for the calculation of maximum-likelihood phylogenetic trees based on the Tamura-Nei model. All methods used are embedded in the MEGA 7 software. The statistical evaluation of the tree topologies was performed by bootstrap analysis with 1000 resamplings.

\section{Culture Conditions and Biosurfactants Extraction}

The strain was routinely cultured on TSA-YE $(6 \mathrm{~g} / \mathrm{l})$ at $30^{\circ} \mathrm{C}$. For biosurfactants production, the strain was grown in flasks containing $200 \mathrm{ml}$ mineral salt medium (MSM) with the following composition: $7 \mathrm{~g} / \mathrm{l} \mathrm{K}_{2} \mathrm{HPO}_{4}, 2 \mathrm{~g} / \mathrm{K} \mathrm{KH}_{2} \mathrm{PO}_{4}$, $1 \mathrm{~g} / \mathrm{l}\left(\mathrm{NH}_{4}\right)_{2} \mathrm{SO}_{4}, 0.5 \mathrm{~g} / \mathrm{l}$ sodium citrate $2 \mathrm{H}_{2} \mathrm{O}$, and $0.1 \mathrm{~g} / \mathrm{l}$ $\mathrm{MgSO}_{4} \times 7 \mathrm{H}_{2} \mathrm{O}(\mathrm{pH}$ 7.0). Glucose was added to MSM to a final concentration of $20 \mathrm{~g} / \mathrm{l}$ (Janek et al., 2010). The flasks were inoculated with overnight liquid culture at a final $\mathrm{OD}_{600}=0.01$ and then incubated at $17^{\circ} \mathrm{C}$ for 4 days under agitation $(180 \mathrm{rpm}$; INFORS Unitron). After incubation, bacteria were removed by centrifugation at $10,000 \times \mathrm{g}$, for $30 \mathrm{~min}$ at $4^{\circ} \mathrm{C}$. The culture supernatant was filtered against a $0.22-\mu \mathrm{m}$ filter.

The supernatant was subjected to drop-collapse assay for rapid screening of biosurfactants production. Briefly, $5 \mu \mathrm{l}$ of supernatant was placed on an oil-coated surface with $1 \mu l$ of methylene blue to improve visualization. The stability of the drop was checked and compared to a negative control (sterile MSM medium). If the liquid contains surfactants, the drops spread because of the reduction of the force or interfacial tension between the liquid drop and the hydrophobic surface (Walter et al., 2010).

A cell-free supernatant was extracted three times with ethyl acetate $(1: 1, \mathrm{v} / \mathrm{v})$. The organic fractions were collected and evaporated under vacuum. The residual crude extract was dissolved in water/acetonitrile (ACN) $(1: 1, \mathrm{v} / \mathrm{v})$ and stored at $4^{\circ} \mathrm{C}$ until analysis.

\section{Time Course of Cell Growth and Lipopeptide Production}

Pseudomonas sp. UCMA 17988 was grown in liquid MSM medium containing $20 \mathrm{~g} / \mathrm{l}$ of glucose. Flasks were inoculated with overnight liquid culture at a final $\mathrm{OD}_{600}=0.01$ and then incubated at $17^{\circ} \mathrm{C}$ for 6 days under agitation (180 rpm; INFORS Unitron). The growth was evaluated every $24 \mathrm{~h}$ by measuring optical density at $600 \mathrm{~nm}$. The production of lipopeptide was measured by HPLC using a previously reported method (Luo et al., 2013).

\section{Antibacterial Effect of Crude Extract by Well-Diffusion Method}

The antibacterial effect of crude extract was analyzed using the well-diffusion technique (Tagg and McGiven, 1971) modified by Audisio et al. (2005). The lawn was obtained by sowing $100 \mu \mathrm{l}$ of a 24-h indicator strain (L. monocytogenes WSLC 1685, S. aureus CIP 53.154, and S. enterica serotype Newport CIP 105629) culture in $20 \mathrm{ml}$ of TSA-YE soft agar $(0.75 \%$, w/v). Fifty microliters of crude extract was poured into wells punched in the lawn of the indicator strain and the plates were incubated at $30^{\circ} \mathrm{C}$ for $24 \mathrm{~h}$. Fifty microliters of diluent (water/ACN, 1:1) was used as negative control. After incubation, plates were examined for the presence of inhibition halos.

\section{HPLC and Mass Spectrometry}

Reverse phased HPLC (Waters Alliance HPLC system with 2695 pump and 2998 PDA detector) was performed at room temperature at $1 \mathrm{ml} / \mathrm{min}$ on a C18 Chromolith SpeedROD RP$18 \mathrm{e}$ column $(4.6 \times 50 \mathrm{~mm}$, Merck Millipore, United States). Mobile phase: $\mathrm{H}_{2} \mathrm{O}$ (0.1\% formic acid)/ACN; 0 min: 50/50, 2 min: 50/50, $22 \mathrm{~min}: 0 / 100,25 \mathrm{~min}: 0 / 100$. The elution was monitored at $220 \mathrm{~nm}$. Fractions were collected and lyophilized prior storage at $-20^{\circ} \mathrm{C}$.

Mass spectrometry analyses were carried out on a MALDI AB Sciex 5800 proteomics analyzer equipped with TOF ion optics and an OptiBeam on-axis laser irradiation with $1000 \mathrm{~Hz}$ repetition rate. The system was calibrated before analysis with a mixture of Angiotensin I, Angiotensin II, Neurotensin, ACTH clip (1-17), ACTH clip (18-39), and mass precision were better than $50 \mathrm{ppm}$. A $1 \mu \mathrm{l}$ volume of biosurfactant solution was mixed with $10 \mu \mathrm{l}$ of alpha-cyano-4-hydroxy-cinnamic-acid (CHCA) matrix prepared in a diluent solution of $50 \% \mathrm{ACN}$ with $0.1 \%$ trifluoroacetic acid. The mixture was spotted on a stainless steel Opti-TOF 384 targets; the droplet was allowed to evaporate before introducing the target into the mass spectrometer. Acquisitions were taken in automatic mode. A laser intensity 
of 3400 was typically employed for ionizing. MS spectra were acquired in the positive reflector mode by summarizing 1000 single spectra $(5 \times 200)$ in the mass range from 700 to $2000 \mathrm{Da}$. $\mathrm{MS} / \mathrm{MS}$ spectra were acquired in positive MS/MS reflector mode by summarizing a maximum of 2500 single spectra $(10 \times 250)$ with a laser intensity of 3900 . For the tandem MS experiments, the acceleration voltage applied was $1 \mathrm{kV}$ and air was used as the collision gas. Gas pressure medium was selected as settings. The fragmentation pattern was used to determine the sequence of the lipopeptide.

\section{NMR Spectroscopy}

Nuclear magnetic resonance spectra were obtained using a Brüker AVIII 600 spectrometer (Brüker, Wissembourg, France) equipped with a $10 \AA$ gradient amplifier and a $5 \mathrm{~mm} \mathrm{CPTX}\left\{{ }^{1} \mathrm{H}\right.$, $\left.{ }^{13} \mathrm{C},{ }^{15} \mathrm{~N}\right\}$ including shielded $z$ gradients. A lyophilized sample was dissolved in acetone-d6. The $1 \mathrm{D}^{1} \mathrm{H}, 2 \mathrm{D}{ }^{1} \mathrm{H}-{ }^{1} \mathrm{H}$ (COSY, TOCSY, NOESY) and ${ }^{1} \mathrm{H}-{ }^{13} \mathrm{C}$ (HSQC, HMBC) spectra were recorded at $298 \mathrm{~K}$.

\section{Inhibition Spectrum of Milkisin}

The minimum inhibitory concentrations (MICs) of purified lipopeptide were evaluated in triplicate by using a microtiter plate dilution assay as outlined by the Clinical \& Laboratory Standards Institute in the CLSI M07-A10 document (CLSI, 2015). Target bacterial strains S. aureus CIP 53.154, S. enterica Newport CIP 105629, S. enterica Typhimurium LMG 7233, S. enterica Mbandaka CIP 105859, S. enterica Dublin CIP 7053, S. enterica Montevideo CIP 104583, L. monocytogenes WSLC 1685, E. coli O157:H7 stx-C267S, E. coli K12 ATCC 1079, Enterococcus faecium CIP 103014T, and Pseudomonas aeruginosa LMG 01242T were grown overnight and adjusted to $5.10^{5} \mathrm{CFU} / \mathrm{ml}$ in Müller Hinton broth (MHB). Lipopeptide concentrations were tested up to $1 \mathrm{mg} / \mathrm{ml}$. The microtiter plates were incubated at $30^{\circ} \mathrm{C}$ until visible growth of the positive control. Cultures without peptides were used as positive controls. Non-inoculated MHB was used as a negative control. MICs were defined as the lowest concentration of an antimicrobial that inhibits the visible growth of a microorganism after overnight incubation.

Four fungal strains were also chosen to test different representative fungal groups: Aspergillus niger (CMPG 814), Cladosporium herbarum (CMPG 38), Mucor hiemalis (CBS 201.65), and Penicillium expansum (CMPG 136). The fungal stock cultures were incubated for 15 days at $25^{\circ} \mathrm{C}$ on malt extract agar (MEA) medium. Each culture was scrapped to recover mycelium and spores which were crushed in sterile water (Ultra Turax $^{\circledR}$, United States) and filtered on a sterile gauze in order to obtain a fungal suspension. Then $1 \mathrm{ml}$ of the final inoculum calibrated at $10^{6}$ spores $/ \mathrm{ml}$ was deposited on Petri dish. The solution of milkisin (20 mg/l) and the four dilutions (2, 1, 0.5, and $0.25 \mathrm{mg} / \mathrm{ml}$ ) were deposited in triplicate on sterile filter paper discs (6 $\mathrm{mm}$ in diameter) placed on the agar surface of Petri dishes according to the agar disc diffusion method (Balouiri et al., 2016). The growth inhibition around the disc was observed after both 48 and $72 \mathrm{~h}$. The sensitivities of the fungal species to the milkisin were determined by measuring the sizes of inhibitory zones (including the diameter of the disc). Tests were performed in triplicate.

\section{RESULTS}

\section{Properties of Pseudomonas sp. UCMA 17988}

Comparison of the $16 S$ rRNA gene sequence (1398 nt, Accession Number: MH016575) with type strains of bacterial species recorded in the GenBank database assigned the strain to the Pseudomonas genus. The closest relative was Pseudomonas helmanticensis $\mathrm{OHA}_{1}{ }^{\mathrm{T}}$ with $99 \%$ pairwise identities (5 nt differences). The next closest relatives with 99\% identity (616 nt differences) were the type strains $P$. baetica $a 390^{\mathrm{T}}$, P. umsongensis Ps3-10, P. jessenii CIP 105274, P. synxantha LMG 2190, P. granadensis LMG 27940, P. reinekei MT1, P. koreensis Ps 9-14, P. mohnii lpA-2, P. vancouverensis DhA-51, P. granadensis F-278,770 ${ }^{\mathrm{T}}$, and P. mandelii CIP 105273. A phylogenetic analysis of $16 S$ rRNA gene sequences was carried out including all the closest related species to Pseudomonas sp. UCMA 17988. According to the maximum-likelihood phylogenetic tree, the strain clustered in a separate branch related to $P$. helmanticensis, $P$. baetica, $P$. reinekei, $P$. umsongensis, $P$. mohnii, $P$. jessenii, and $P$. vancouverensis (data not shown).

The resolution of $16 S$ rRNA gene sequences at the intrageneric level being low, the gene sequence for RpoD, providing better resolution, has been studied (Mulet et al., 2010; Rajwar and Sahgal, 2016). Indeed, among Pseudomonas genus, the housekeeping rpoD gene possesses the highest discriminatory power when compared to other useful genes to analyze phylogenetic relationships among the genera (e.g., rpoB, gyrB, $16 S$ $r R N A$ gene sequences) (Mulet et al., 2010). The comparison of partial $r p o D$ nucleotide sequences revealed the highest pairwise identity to $P$. helmanticensis $\mathrm{OHA}_{11}^{\mathrm{T}}$ (95\%; 35 nt differences) and about $94 \%$ with P. granadensis LMG 27940, P. granadensis F-278,770 ${ }^{\mathrm{T}}$, and $P$. moraviensis DSM $16007^{\mathrm{T}}$. The nucleotide sequence of $r p o D$ gene of the strain reported here (698 nt, accession number: MH094851) clustered in P. koreensis subgroup (Figure 1).

Pseudomonas sp. UCMA 17988 showed antibacterial activity by the spot-on-lawn method against various Gram-negative and Gram-positive bacterial pathogens. Indeed, inhibition could be observed for L. monocytogenes WSLC 1685, S. aureus CIP 53.154, and S. enterica serotype Newport CIP 105629 (Figure 2). Interestingly, no activity could be observed for the other Salmonella serotypes tested (Typhimurium, Dublin, Mbandaka, and Montevideo).

\section{Extraction and Structural Analysis of Biosurfactants}

The hypothesis that Pseudomonas sp. UCMA 17988 produces biosurfactants was explored in order to explain the antimicrobial activity of the strain. After a 4-day bacterial growth in MSM medium with glucose as sole carbon source, the highly reduced surface tension of the cell-free supernatant indicated 


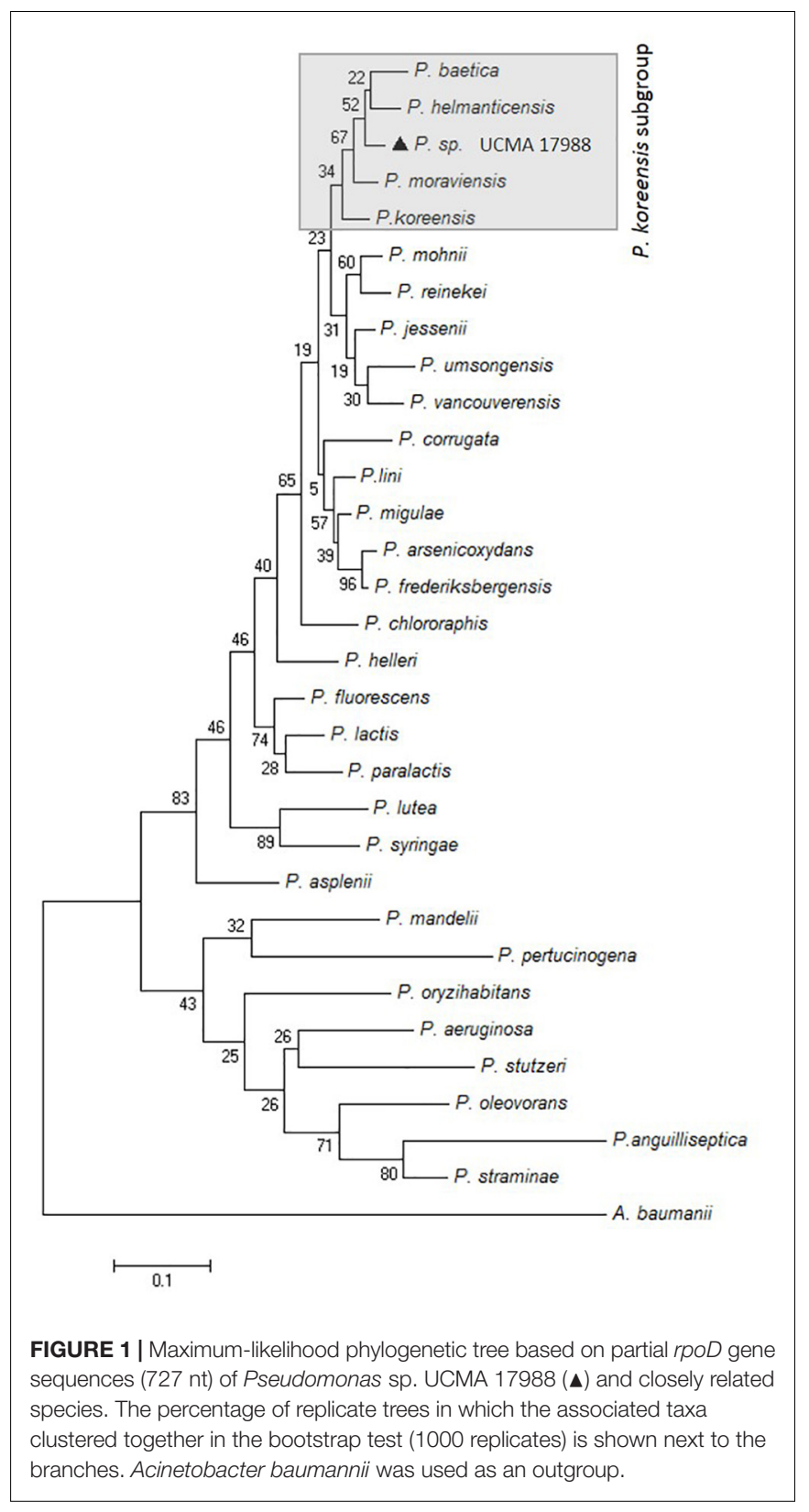

the production of biosurfactants by the strain (Supplementary Figure S1). Biosurfactants produced were isolated using a twostep purification method. First, biosurfactants were partially purified from the culture supernatant by ethyl acetate extraction. After the first step of purification, the antibacterial activity of the extract was checked using the well-diffusion method (Figure 2). Biosurfactants were further purified from the extract using reverse phase HPLC on a C18 column. HPLC chromatogram highlights four peaks, with retention time at $6.84,7.46,8.52$, and $9.20 \mathrm{~min}$ (Figure 3).

Hereafter, collected fractions were analyzed by MALDI-TOF mass spectrometry. The spectra also highlighted the presence of four molecules (Figure 4). Two intense pseudomolecular ions $[\mathrm{M}+\mathrm{H}]+$ at $\mathrm{m} / z \quad 1409.49$ and 1395.48 were observed.

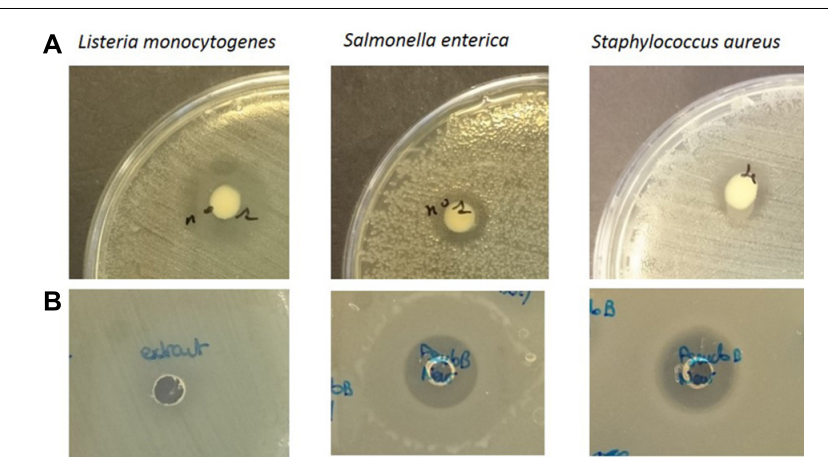

FIGURE 2 | Spot on the lawn assay of Pseudomonas sp. UCMA 17988 (A) and well diffusion assay of biosurfactants crude extract (B) against Listeria monocytogenes WSLC 1685, Salmonella enterica Newport CIP 105629, and Staphylococcus aureus CIP 53.154.

Corresponding sodium and potassium adducts were also found at $\mathrm{m} / z[\mathrm{M}+\mathrm{Na}]+$ at 1417 and 1431.60 and $\mathrm{m} / z[\mathrm{M}+\mathrm{K}]+$ at 1433.57 and 1447.57 respectively. The two other molecules could be detected through their potassium and/or sodium adducts $(\mathrm{m} / z[\mathrm{M}+\mathrm{Na}]+$ at $1403 ; \mathrm{m} / z[\mathrm{M}+\mathrm{K}]+$ at 1419.57 and 1461.58). The presence of four molecules harboring a difference of $14 \mathrm{Da}$ was consistent with the presence of lipopeptides isoforms. Indeed, such difference is typical of the addition or substitution of a methyl group in the fatty acid chain. A MS/MS analysis was performed on the dominant $[\mathrm{M}+\mathrm{H}]+$ ion $(\mathrm{m} / \mathrm{z}$ at 1409.49). The fragmentation spectrum obtained is shown in Figure 5. Fragments were assigned by subtraction of the different peaks between them. The ions with $284 \mathrm{Da}$ and $86 \mathrm{Da}$ masses were observed and respectively correspond to fragment 3-hydroxy-fatty acid-Leu/Ile and immonium ion of leucine or isoleucine. The following linear sequence was proposed: 3HDA-Leu/Ile1-Asp2-Thr3-Leu/Ile4-Leu/Ile5-Ser6-Leu/Ile7-

Gln8-Leu/Ile9-Leu/Ile10-Glu11 with cyclisation between Thr3 and Glu11.

In order to confirm the isoforms hypothesis, three other molecules underwent a fragmentation process. Indeed, the MS/MS results confirmed the difference of $14 \mathrm{Da}$ only in fragments carrying the fatty acid chain indicating the presence of four isoforms of the same lipopeptide (Supplementary Figures S2-S4). In order to confirm the lipopeptide sequence, especially because of the high proportion of leucine and/or isoleucine in the peptidic moiety, an NMR analysis was performed (Supplementary Table S1).

$1 \mathrm{D}$ and $2 \mathrm{D}{ }^{1} \mathrm{H}$ and ${ }^{13} \mathrm{C}$ NMR spectra contained predominantly resonances that were characteristic of peptides. In the low field region (6-11 ppm) of the $1 \mathrm{D}{ }^{1} \mathrm{H}$ NMR spectrum (Figure 5A), a broad signal at $10.78 \mathrm{ppm}$ corresponding to an acidic proton (Asp2), signals of $11 \mathrm{NH}$ protons and a pair of signals characteristic of NH2 protons were observed. Between 1 and $6 \mathrm{ppm}$ (Figure 5B), the characteristic signals of the aliphatic $\mathrm{CH}(\alpha, \beta, \gamma$, and $\delta)$ protons appeared with residual solvents (water and acetone). Finally, between 0.8 and $1 \mathrm{ppm}$ some signals corresponding to 45 protons that is to say 15 methyl groups were observed. 


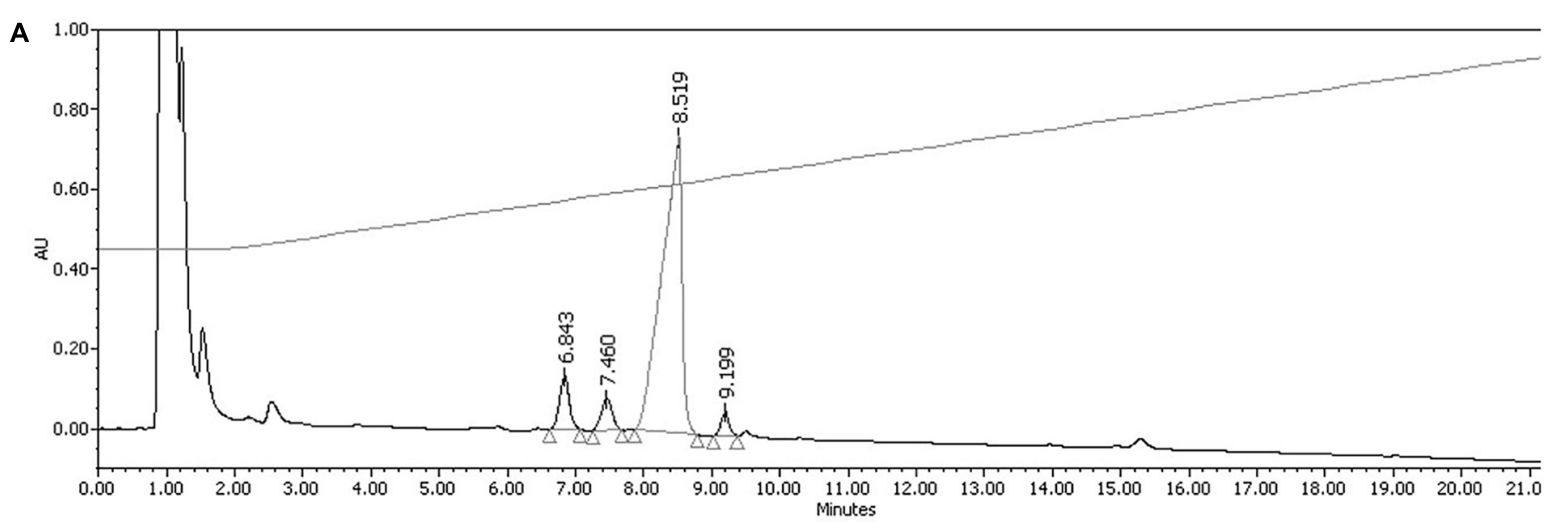

B

\begin{tabular}{llll}
\hline Retention time $(\min )$ & {$[\mathrm{M}+\mathrm{H}]+$} & {$[\mathrm{M}+\mathrm{Na}]+$} & {$[\mathrm{M}+\mathrm{K}]+$} \\
\hline 6.84 & $\mathrm{ND}$ & 1403 & 1419,57 \\
7.46 & 1395,48 & 1417 & 1433,57 \\
8.52 & 1409,49 & 1431,60 & 1447,57 \\
9.20 & ND & ND & 1461,58 \\
\hline
\end{tabular}

FIGURE 3 | Purification and mass spectrometry analysis of biosurfactants isoforms produced by Pseudomonas sp. UCMA 17988. (A) Reverse-phase HPLC. Elution was carried out using $\mathrm{H} 2 \mathrm{O} / \mathrm{ACN} /$ formic acid $0.1 \%(\mathrm{v} / \mathrm{v})$ solvent system and monitored at $220 \mathrm{~nm}$. (B) Pseudo-molecular ions detected by MALDI-TOF analysis. ND, not detected.

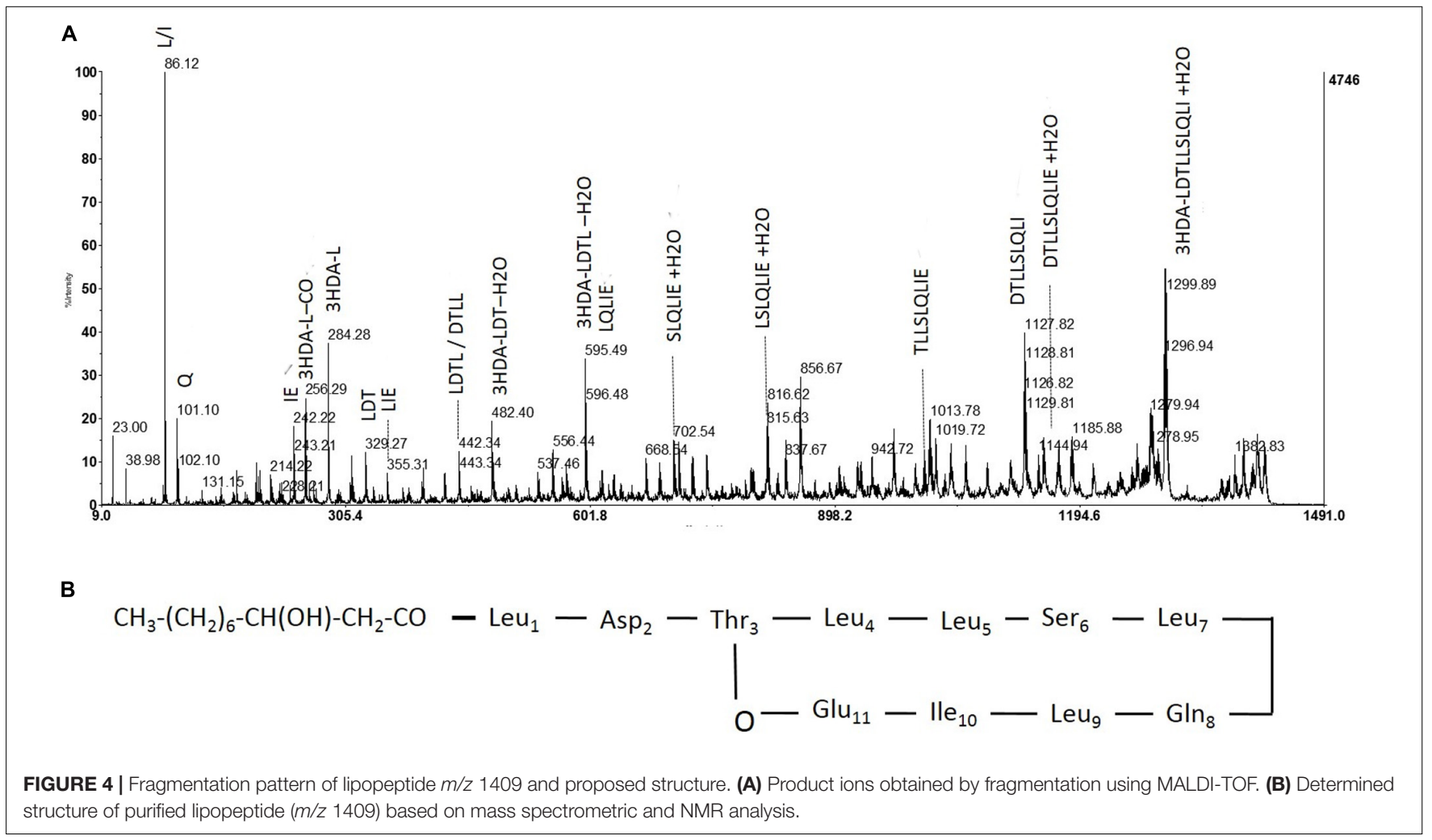


A
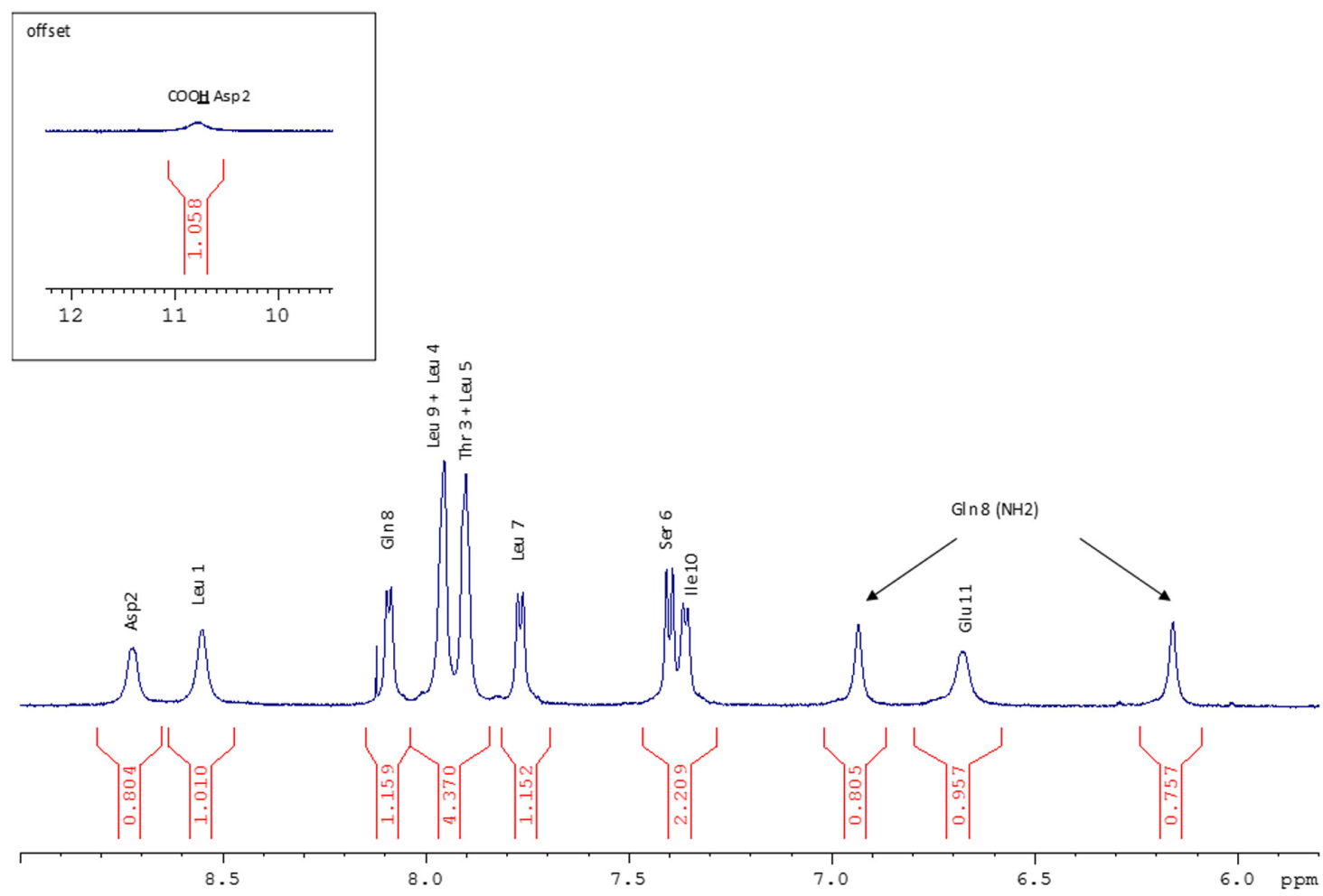

B

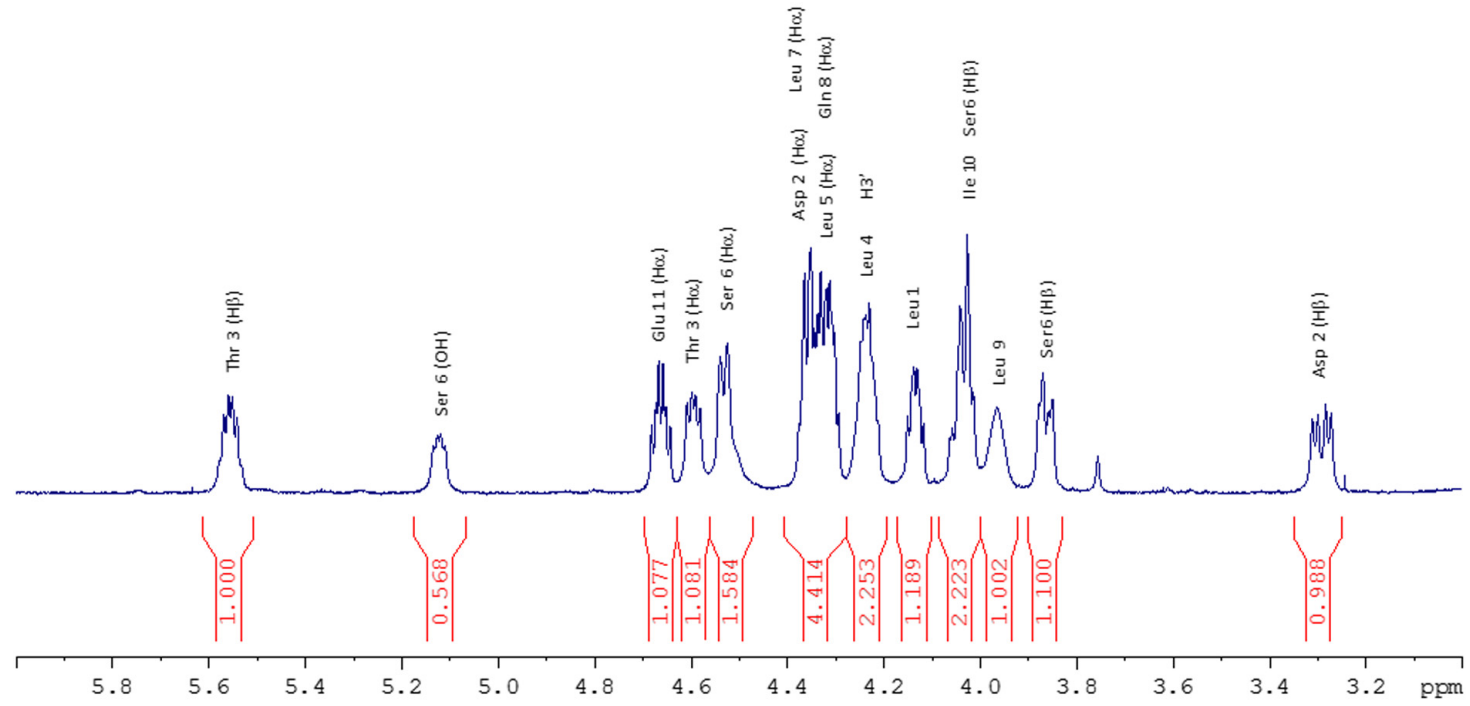

FIGURE 5 | (A) NH zone of the ${ }^{1} \mathrm{H}$ NMR spectrum (600 MHz, $298 \mathrm{~K}$, Acetone- $\left.\mathrm{d}_{6}\right)$. (B) $\mathrm{H} \alpha$ zone of the ${ }^{1} \mathrm{H}$ NMR spectrum (600 MHz, $298 \mathrm{~K}$, Acetone- $\left.\mathrm{d}_{6}\right)$.

The ${ }^{1} \mathrm{H}$ NMR spectrum was assigned by the standard procedure (Wüthrich, 1986). The first step involved the analysis of COSY, TOCSY (Figure 6A), and NOESY (Figure 6B) spectra to identify spin systems that are characteristic of particular amino acids. The COSY spectrum showed correlations $\mathrm{HNi}-\mathrm{H} \alpha \mathrm{I}$ for each residue which excluded the presence of a proline in the lipopeptide. Then the spin system residues were assigned to specific locations in their sequence by the observation of
NOE between resonances of sequentially adjacent residues, $\mathrm{HNi}$ $\mathrm{HNi}+1, \mathrm{H} \alpha \mathrm{i}-\mathrm{HNi}+1$, and $\mathrm{H} \beta \mathrm{i}-\mathrm{HNi}+1$. The $\mathrm{NH}$ proton of Leu1, which is the only Leu out of the macrocycle, was identified in accordance with the literature (Weisshoff et al., 2014) and from a NOE correlation with H2' (2.55 ppm) as the most deshielded Leu $\mathrm{NH}(8.55 \mathrm{ppm})$ and then served as a sequential starting point. The observation of NOES due to $\mathrm{HNi}-\mathrm{HNi}+1$ and $\mathrm{H} \alpha \mathrm{i}-\mathrm{HNi}+1$ allowed assignment of fragments placed in a unique position 


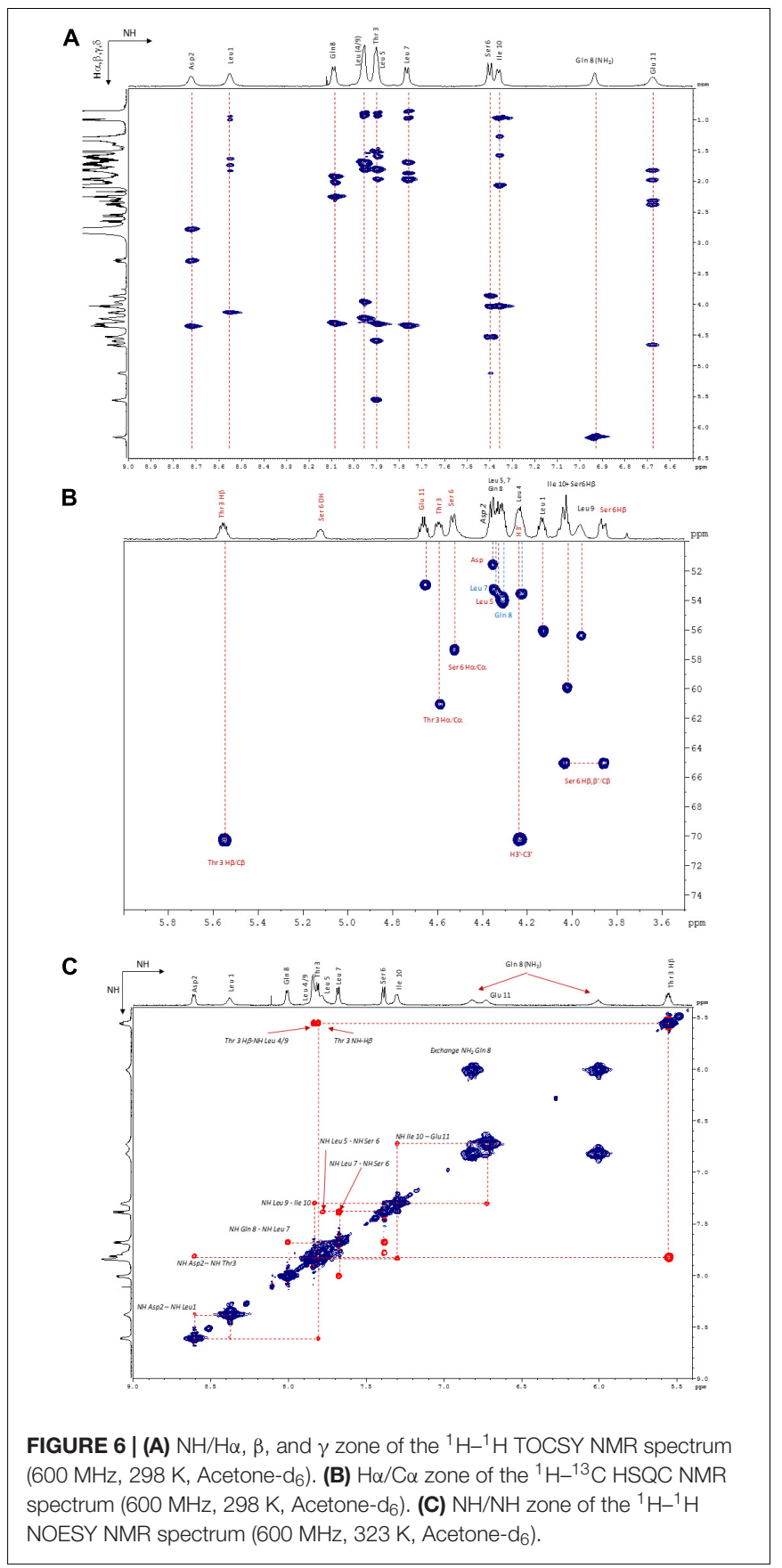

in the sequence. The $\mathrm{NH}$ proton of Leul is weakly correlated with $\mathrm{NH}$ proton of Asp residue which is correlated to Thr3 $\mathrm{NH}$ suggesting Asp residue located in position 2. Once the assignment of the protons of each residue was realized, the ${ }^{1} \mathrm{H}-{ }^{13} \mathrm{C}$ HSQC and the ${ }^{1} \mathrm{H}-{ }^{13} \mathrm{C} \mathrm{HMBC}$ spectra allowed the assignment of the corresponding protonated and quaternary carbons. The $2 \mathrm{D}$ ${ }^{1} \mathrm{H}-{ }^{13} \mathrm{C}$ HSQC spectrum (Figure 6C) pointed out two carbinol methine carbons $(\mathrm{CHOH})$ at $70.33 \mathrm{ppm}$ corresponding to the $\mathrm{C} \beta$ of Thr3 (attached to Thr3 $\mathrm{H} \beta$ at $5.56 \mathrm{ppm}$ ) and to the C3' (attached to H3' at $4.24 \mathrm{ppm}$ ) of the fatty chain. The downfield chemical shift of Thr3 H $\beta$ (5.56 ppm) indicated that the hydroxyl group was part of an ester linkage implying that the cyclization involved this residue. All ${ }^{1} \mathrm{H}$ and ${ }^{13} \mathrm{C}$ resonance assignments are summarized in Table 1 (Supporting Information).

Consequently, ${ }^{1} \mathrm{H},{ }^{13} \mathrm{C}$ NMR, as well as MSMS data confirm the sequence represented in Figure 4.

\section{Time Course of Cell Growth and Lipopeptide Production}

The time course of the cultivation is shown in Figure 7. Lipopeptides concentration increased rapidly during the exponential phase of growth thereby suggesting that the molecules are produced as primary metabolites accompanying cellular biomass formation. The average maximum yield of lipopeptides $(47.6 \pm 1.4 \mathrm{mg} / \mathrm{l})$ was reached at $96 \mathrm{~h}$ cultivation. During cell apoptosis period (120-144 h), the lipopeptides production dramatically decreased by $78.6 \%$.

\section{Antimicrobial Activity of Milkisin}

The antibacterial activity of the major isoform was evaluated against 11 Gram-positive and Gram-negative bacterial strains. Antibacterial activity was observed against S. aureus CIP 53.154 and S. enterica Newport CIP 105629 strains with MIC of 0.5 and $1 \mathrm{mg} / \mathrm{ml}$, respectively. The antifungal activity was also investigated against four strains representative of fungal groups (P. expansum CMPG 136, M. hiemalis CBS 201.65, A. niger CMPG 814, and C. herbarum CMPG 38). Only a weak antifungal activity was observed against $P$. expansum CMPG 136 (MIC of $20 \mathrm{mg} / \mathrm{l})$. The antimicrobial spectrum of milkisin is presented in Table 1.

TABLE 1 | Antimicrobial activity of milkisin.

Microorganism

$\operatorname{MIC}(\mathrm{mg} / \mathrm{ml})$

Staphylococcus aureus CIP 53.154

0.5

Salmonella enterica serotype Newport CIP 105629

Salmonella enterica serotype Typhimurium LMG 7233

Salmonella enterica serotype Dublin CIP 7053

1

$>1$

Salmonella enterica serotype Mbandaka CIP 105859

Salmonella enterica serotype Montevideo CIP 104583

Escherichia coli O157:H7 stx-C267S

Listeria monocytogenes WSLC 1685

Pseudomonas aeruginosa LMG 01242T

Escherichia coli K12 ATCC 1079

Enterococcus faecium CIP 103014T

Aspergillus niger CMPG 814

Cladosporium herbarum CMPG 38

$>1$

$>1$

$>1$

$>1$

$>1$

$>1$

$>1$

$>1$

$>20$

$>20$

$>20$

Penicillium expansum CMPG 136

20

Antibacterial activity was determined by broth microdilution (maximum concentration tested: $1 \mathrm{mg} / \mathrm{ml}$. Antifungal activity was determined by agar diffusion test (maximum concentration tested: 20 mg/ml). 


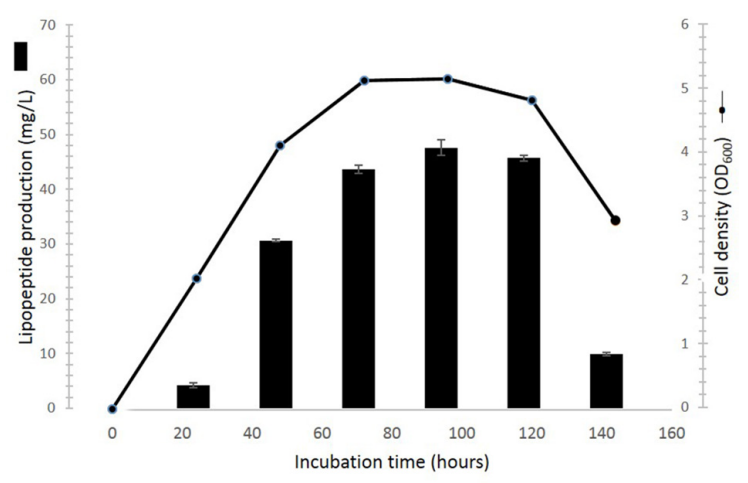

FIGURE 7 | Time course of cell growth and lipopeptides production of Pseudomonas sp. UCMA 17988 in glucose-MSM medium. Cell growth was evaluated by optical density measurement at $600 \mathrm{~nm}$. Lipopeptide was quantified by HPLC.

\section{DISCUSSION}

In the present study, we aim to describe the production of new lipopeptides by Pseudomonas sp. UCMA 17988 isolated from raw milk. To our knowledge, the sequence did not correspond to any known lipopeptide in the literature or recorded in the NORINE database. Nevertheless, the sequence was very close to members of the amphisin group since the peptidic chain was composed of 11 amino acids, 6 of which are conserved among the family (Figure 8). The name "milkisin," chosen for this new lipopeptide, refers to the matrix in which Pseudomonas sp. UCMA 17988 has been isolated. The major isoform $(1409 \mathrm{~m} / z)$, composed of 10 carbons in the lipidic chain, was named milkisin C. The molecule has been recorded in the NORINE database under the identification number NOR01358. The three other isoforms of 1381,1395 , and $1423 \mathrm{~m} / z$, that are concomitantly produced, were named milkisin A, B, and D, respectively. As far as we know, only two Pseudomonas strains isolated from dairy product were shown to produce cyclic lipopeptides. However, those two strains, closely related to $P$. tolaasii, were shown to produce isoforms belonging to another family (viscosin) (Reybroeck et al., 2014).

The present study provides evidence that the production of milkisin is tightly coupled to cell proliferation. This is consistent with the results obtained for other members of the amphisin group, such as tensin and amphisin production for example (Nielsen et al., 2000; Koch et al., 2002). Indeed, the Pseudomonas sp. UCMA 17988 starts producing milkisin at the beginning of the exponential phase. Lipopeptides accumulate during the stationary phase before to dramatically decrease along with cell death. These observations are also consistent with the synthesis of other lipopeptides among the Bacillus and Pseudomonas genera (Saikia et al., 2012; Luo et al., 2013).

In the literature, several lipopeptides have potent antifungal potential and antibacterial activities. However, the antibacterial activity is mostly moderate and confined to Gram-positive bacteria since Gram-negative bacteria seem to be better protected thanks to their different cell envelopes (Reder-Christ et al., 2012). Few studies focusing on the antimicrobial potential of members of the amphisin group composed of anikasin, amphisin, arthrofactin, lokisin, tensin, and pholipeptin were conducted. These studies highlighted the weak antimicrobial potential of this group. For example, in a comparative study, $1 \mathrm{mg} / \mathrm{ml}$ of arthrofactin did not show inhibition of a large panel of Gram-positive and Gram-negative bacteria (E. coli, Klebsiella pneumoniae, Citrobacter freundii, $P$. aeruginosa, Serratia marcescens, S. aureus, Staphylococcus epidermidis, Staphylococcus simulans, Micrococcus luteus, E. faecium, Bacillus subtilis, Bacillus megaterium, Listeria welshimeri). A weak activity was only observed against Corynebacterium sp., Mycobacterium smegmatis, and Arthrobacter crystallopoietes (Reder-Christ et al., 2012). The newly discovered anikasin did not show any antibacterial activity at the maximum concentration tested (1 $\mathrm{mg} / \mathrm{ml}$ ) against a variety of different species (B. subtilis, S. aureus, E. coli, P. aeruginosa, and Mycobacterium vaccae) and was only weakly active against E. faecium (Götze et al., 2017). In addition no antifungal properties were observed. Antifungal activity was only reported against Rhizoctonia solani with tensin (Nielsen et al., 2000). Consistently with these previous reports, milkisin also only has weak antibacterial properties against the Gram-positive and Gram-negative strains S. aureus and S. enterica Newport, respectively, and a weak antifungal activity. Surprisingly, no activity could be observed against the four other Salmonella strains tested. However, the absence of activity might be attributed to species-specific variations of these strains in the cell-surface or in the cell wall composition. Indeed, it is widely accepted that the primary target of lipopeptides is the membrane. The membrane association is driven both by the polar amino acid residues that initially allow interaction with the polar head groups of the phospholipids and by the following incorporation of the fatty acids into the membrane core. The disintegration of the lipid bilayer causes leakage of ions from the cells (Sinnaeve et al., 2009). The size of the acyl chain appears to be crucial for the antimicrobial activity of lipopeptides, presumably

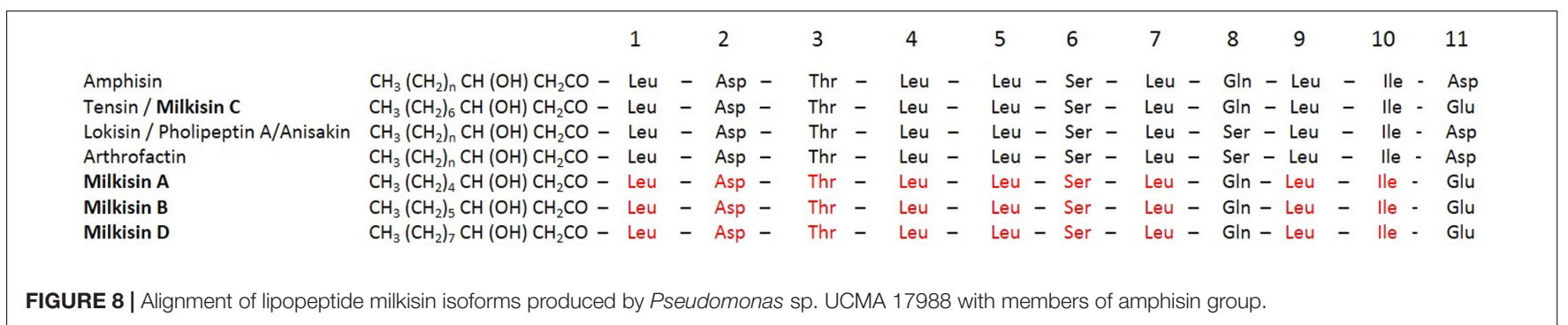


due to a different interaction with the cell membrane. Indeed, few studies revealed a difference in the antimicrobial potency of lipopeptide analogs, the one with longer acyl chain being the most potent (Kracht et al., 1999; Tabbene et al., 2011). Based on these studies, we may speculate that isoforms $\mathrm{C}$ and $\mathrm{D}$ of milkisin would be more active than shorter isoforms A and B. However, specific activity of each isoform of milkisin could not be analyzed in our study because of the very low amount produced for minor isoforms $\mathrm{A}, \mathrm{B}$, and $\mathrm{D}$. More specific mechanisms may also be evolved in some cases, e.g., inhibition of the cell-wall synthesis (Schneider et al., 2009; Reder-Christ et al., 2012). The mode of action of six structurally different Pseudomonas lipopeptides, including arthrofactin which is closely related to milkisin, was investigated using a model membrane system (Reder-Christ et al., 2012). The study revealed a high membrane affinity. However, arthrofactin was shown to have a median incorporation tendency and was not able to disrupt the model membrane at $50 \mu \mathrm{g} / \mathrm{ml}$ (Reder-Christ et al., 2012). This may explain the weak antimicrobial activity of both milkisin and arthrofactin.

Until today, lipopeptides have received considerable attention especially for their antifungal and surfactant properties. However, it appears that these molecules have additional natural roles allowing the bacteria to survive in the environment. Indeed, these molecules have been thought to confer competitive advantage in interactions with other organisms such as viruses, mycoplasmas, bacteria, fungi, and oomycetes (Raaijmakers et al., 2010). Some lipopeptides were proven to confer protection against predation by protozoa. For example, massetolide and viscosin are involved in the protection of Pseudomonas fluorescens strains against the amoeba Naegleria americana causing lysis of the predator (Mazzola et al., 2009). Biosurfactants can change surface viscosity thereby influencing cell differentiation and motility giving advantage to surface colonization (Raaijmakers et al., 2010). Some of these molecules also play an important role in surface attachment and biofilm formation. Indeed, the disruption of $\operatorname{arf} B$, involved in arthrofactin production, decreases swarming activity, and enhances biofilm formation (Roongsawang et al., 2003). Moreover, the chelation of metal ions has been described for several lipopeptides produced by Bacillus species (Raaijmakers et al., 2010). Regarding the antimicrobial activity of milkisin, this lipopeptide most probably confers another advantage than antagonism to the strain. Therefore, it would be interesting in the future to evaluate its role against predation or colonization and biofilm formation.

The analysis of the single-gene sequence indicates that Pseudomonas sp. UCMA 17988 belongs to a putative new species of the $P$. koreensis subgroup. However, in order to confirm this hypothesis, comparative bioinformatics analyses of whole genomes of $P$. koreensis subgroup species will have to be performed in the future (Mulet et al., 2010). Moreover, in further analyses, the description of this putative new species would also have to be detailed (e.g., phenotypic characteristics, cellular fatty acid composition). Among the P. koreensis subgroup, five species have been described to date: $P$. koreensis, $P$. moraviensis, $P$. helmanticensis, and P. granadensis species (described in soil samples all around the world) and baetica as a marine fish pathogen (Mulet et al., 2010; López et al., 2012; RamírezBahena et al., 2014). Only three isolates of $P$. koreensis subgroup, isolated from water collected in a Mexican oasis, were found to produce biosurfactants. This production confers antagonistic activity toward B. subtilis and Exiguobacterium aurantiacum but not Enterococcus faecalis, S. aureus, E. coli, Salmonella Typhi, and Bacillus liquefaciens strains. However, as far as we know, these biosurfactants have never been characterized (Toribio et al., 2011).

Interestingly, milkisin is involved in the antagonistic effect of the strain against a Gram-negative bacterial strain (Salmonella Newport CIP 105629) thus conferring an atypical activity to the Pseudomonas sp. UCMA 17988 strain. Gram-negative bacteria are very common in dairy foods where they can reach a high level. Most of them are regularly considered as indicators of poor hygiene or may constitute a health risk if pathogenic. Nevertheless, some of them may also positively contribute to the quality of dairy products (Quigley et al., 2013). As already mentioned, Pseudomonas genus is mostly known for its spoilage potential. However, some strains producing such antimicrobial lipopeptides may contribute to the antimicrobial barrier against pathogens such as Salmonella or S. aureus in raw milk. In perspective, it might be interesting to characterize the spoilage potential of the strain Pseudomonas sp. UCMA 17988 in the near future and to search for new lipopeptide producers in raw milk.

Pseudomonas species are also associated to plant phyllosphere and rhizosphere and can be found in the dominant microbiota during the whole shelf life of leafy greens (Dees et al., 2015) and pre-prepared vegetables (Jackson et al., 2013). Because Salmonella is an important cause of foodborne outbreaks (Callejón et al., 2015) associated to the consumption of vegetables, the presence of such Pseudomonas strains as a protective culture might be of interest and would deserve to be investigated.

\section{AUTHOR CONTRIBUTIONS}

MSc performed the laboratory experiments, analyzed the data, and written up the manuscript. JG contributed to laboratory experiments and data analysis. $\mathrm{HO}$ and MSe performed the NMR experiments and analyzed the data. BB performed the mass spectrometry analysis. DG and VS performed the antifungal analysis. ND supervised the entire study. All authors proofread and reviewed the manuscript.

\section{FUNDING}

The authors express gratitude to Organisation de Defense et de Gestion des AOP Laitières de Normandie for funding this research.

\section{SUPPLEMENTARY MATERIAL}

The Supplementary Material for this article can be found online at: https://www.frontiersin.org/articles/10.3389/fmicb.2018. 01030/full\#supplementary-material 


\section{REFERENCES}

Arslan, S., Eyi, A., and Özdemir, F. (2011). Spoilage potentials and antimicrobial resistance of Pseudomonas spp. isolated from cheeses. J. Dairy Sci. 94, 5851-5856. doi: 10.3168/jds.2011-4676

Audisio, M. C., Terzolo, H. R., and Apella, M. C. (2005). Bacteriocin from honeybee beebread Enterococcus avium, active against Listeria monocytogenes. Appl. Environ. Microbiol. 71, 3373-3375. doi: 10.1128/aem.71.6.3373-3375.2005

Balouiri, M., Sadiki, M., and Ibnsouda, S. K. (2016). Methods for in vitro evaluating antimicrobial activity: a review. J. Pharm. Anal. 6, 71-79. doi: 10.1016/j.jpha. 2015.11.005

Callejón, R. M., Rodríguez-Naranjo, M. I., Ubeda, C., Hornedo-Ortega, R., GarciaParrilla, M. C., and Troncoso, A. M. (2015). Reported foodborne outbreaks due to fresh produce in the United States and European Union: trends and causes. Foodborne Pathog. Dis. 12, 32-38. doi: 10.1089/fpd.2014.1821

CLSI (2015). M07-A10: Methods for Dilution Antimicrobial Susceptibility Tests for Bacteria that Grow Aerobically; Approved Standard. Wayne, PA: Clinical and Laboratory Standards Institute.

Cousin, M. A., Jay, J. M., and Vasavada, P. C. (2001). Compendium of Methods for the Microbiological Examination of Foods. Washington, DC: American Public Health Association.

Coutte, F., Lecouturier, D., Dimitrov, K., Guez, J.-S., Delvigne, F., Dhulster, P., et al. (2017). Microbial lipopeptide production and purification bioprocesses, current progress and future challenges. Biotechnol. J. 12:7. doi: 10.1002/biot.201600566

De Jonghe, V., Coorevits, A., Van Hoorde, K., Messens, W., Van Landschoot, A., De Vos, P., et al. (2011). Influence of storage conditions on the growth of Pseudomonas species in refrigerated raw milk. Appl. Environ. Microbiol. 77, 460-470. doi: 10.1128/AEM.00521-10

Dees, M. W., Lysøe, E., Nordskog, B., and Brurberg, M. B. (2015). Bacterial communities associated with surfaces of leafy greens: shift in composition and decrease in richness over time. Appl. Environ. Microbiol. 81, 1530-1539. doi: 10.1128/aem.03470-14

Edgar, R. C. (2004). MUSCLE: a multiple sequence alignment method with reduced time and space complexity. BMC Bioinformatics 5:113. doi: 10.1186/1471-21055- 113

Flissi, A., Dufresne, Y., Michalik, J., Tonon, L., Janot, S., Noé, L., et al. (2016). Norine, the knowledgebase dedicated to non-ribosomal peptides, is now open to crowdsourcing. Nucleic Acids Res. 44, D1113-D1118. doi: 10.1093/nar/ gkv1143

Götze, S., Herbst-Irmer, R., Klapper, M., Görls, H., Schneider, K. R. A., Barnett, R., et al. (2017). Structure, biosynthesis, and biological activity of the cyclic lipopeptide anikasin. ACS Chem. Biol. 12, 2498-2502. doi: 10.1021/acschembio. 7 b00589

Herrera, A. G. (2000). Psychrotrophic Microorganisms Agar Plate Methods, Homogenization, and Dilutions, in Food Microbiology Protocols. New Jersey, NJ: Humana Press, 3-10. doi: 10.1385/1-59259-029-2:3

Inès, M., and Dhouha, G. (2015). Lipopeptide surfactants: production, recovery and pore forming capacity. Peptides 71, 100-112. doi: 10.1016/j.peptides.2015. 07.006

Jackson, C. R., Randolph, K. C., Osborn, S. L., and Tyler, H. L. (2013). Culture dependent and independent analysis of bacterial communities associated with commercial salad leaf vegetables. BMC Microbiol. 13:274. doi: 10.1186/14712180-13-274

Janek, T., Łukaszewicz, M., Rezanka, T., and Krasowska, A. (2010). Isolation and characterization of two new lipopeptide biosurfactants produced by Pseudomonas fluorescens BD5 isolated from water from the Arctic archipelago of Svalbard. Bioresour. Technol. 101, 6118-6123. doi: 10.1016/j.biortech.2010. 02.109

Kapadia, S. G., and Yagnik, B. N. (2013). Current trend and potential for microial biosurfactants. Asian J. Exp. Biol. Sci. 4:8. doi: 10.1080/07388551.2016.1269053

Koch, B., Nielsen, T. H., Sørensen, D., Andersen, J. B., Christophersen, C., Molin, S., et al. (2002). Lipopeptide production in Pseudomonas sp. strain DSS73 is regulated by components of sugar beet seed exudate via the Gac two-component regulatory system. Appl. Environ. Microbiol. 68, 4509-4516. doi: 10.1128/AEM.68.9.4509-4516.2002

Kracht, M., Rokos, H., Ozel, M., Kowall, M., Pauli, G., and Vater, J. (1999). Antiviral and hemolytic activities of surfactin isoforms and their methyl ester derivatives. J. Antibiot. 52, 613-619. doi: 10.7164/antibiotics.52.613
Larpin-Laborde, S., Imran, M., Bonaïti, C., Bora, N., Gelsomino, R., Goerges, S., et al. (2011). Surface microbial consortia from Livarot, a French smear-ripened cheese. Can. J. Microbiol. 57, 651-660. doi: 10.1139/w11-050

López, J. R., Diéguez, A. L., Doce, A., De la Roca, E., De la Herran, R., Navas, J. I., et al. (2012). Pseudomonas baetica sp. Nov., a fish pathogen isolated from wedge sole, Dicologlossa Cuneata (Moreau). Int. J. Syst. Evol. Microbiol. 62(Pt 4), 874-882. doi: 10.1099/ijs.0.030601-0

Luo, Y., Guoyi, Z., Zhen, Z., Xiaohui, W., Wei, R., and Qirong, S. (2013). Optimization of medium composition for lipopeptide production from Bacillus subtilis N7 using response surface methodology. Korean J. Microbiol. Biotechnol. 41, 52-59. doi: 10.4014/kjmb.1207.07020

Mallet, A., Guéguen, M., Kauffmann, F., Chesneau, C., Sesboué, A., and Desmasures, N. (2012). Quantitative and qualitative microbial analysis of raw milk reveals substantial diversity influenced by herd management practices. Int. Dairy J. 27, 13-21. doi: 10.1016/j.idairyj.2012.07.009

Mazzola, M., de Bruijn, I., Cohen, M. F., and Raaijmakers, J. M. (2009). Protozoaninduced regulation of cyclic lipopeptide biosynthesis is an effective predation defense mechanism for Pseudomonas fluorescens. Appl. Environ. Microbiol. 75, 6804-6811. doi: 10.1128/AEM.01272-09

Montel, M.-C., Buchin, S., Mallet, A., Delbes-Paus, C., Vuitton, D. A., Desmasures, N., et al. (2014). Traditional cheeses: rich and diverse microbiota with associated benefits. Int. J. Food Microbiol. 177, 136-154. doi: 10.1016/j. ijfoodmicro.2014.02.019

Mulet, M., Lalucat, J., and García-Valdés, E. (2010). DNA sequence-based analysis of the Pseudomonas species. Environ. Microbiol. 12, 1513-1530. doi: 10.1111/j. 1462-2920.2010.02181.x

Nielsen, T. H., Thrane, C., Christophersen, C., Anthoni, U., and Sørensen, J. (2000). Structure, production characteristics and fungal antagonism of tensin a new antifungal cyclic lipopeptide from Pseudomonas fluorescens Strain 96.578. J. Appl. Microbiol. 89, 992-1001. doi: 10.1046/j.1365-2672.2000.01201.x

Quigley, L., O’Sullivan, O., Stanton, C., Beresford, T. P., Ross, R. P., Fitzgerald, G. F., et al. (2013). The complex microbiota of raw milk. FEMS Microbiol. Rev. 37, 664-698. doi: 10.1111/1574-6976.12030

Raaijmakers, J. M., De Bruijn, I., Nybroe, O., and Ongena, M. (2010). Natural functions of lipopeptides from Bacillus and Pseudomonas: more than surfactants and antibiotics. FEMS Microbiol. Rev. 34, 1037-1062. doi: 10.1111/ j.1574-6976.2010.00221.x

Rajwar, A., and Sahgal, M. (2016). Phylogenetic relationships of fluorescent Pseudomonads deduced from the sequence analysis of 16S rRNA, Pseudomonasspecific and RpoD genes. 3 Biotech. 6:80. doi: 10.1007/s13205-016-0386- $\mathrm{x}$

Ramírez-Bahena, M. H., Cuesta, M. J., Flores-Félix, J. D., Mulas, R., Rivas, R., Castro-Pinto, J., et al. (2014). Pseudomonas helmanticensis sp. Nov., isolated from forest soil. Int. J. Syst. Evol. Microbiol. 64(Pt 7), 2338-2345. doi: 10.1099/ ijs.0.063560-0

Reder-Christ, K., Schmidt, Y., Dörr, M., Sahl, H. G., Josten, M., Raaijmakers, J. M., et al. (2012). Model membrane studies for characterization of different antibiotic activities of lipopeptides from Pseudomonas. Biochim. Biophys. Acta 1818, 566-573. doi: 10.1016/j.bbamem.2011.08.007

Reybroeck, W., De Vleeschouwer, M., Marchand, S., Sinnaeve, D., Heylen, K., De Block, J., et al. (2014). Cyclic lipodepsipeptides produced by Pseudomonas spp. naturally present in raw milk induce inhibitory effects on microbiological inhibitor assays for antibiotic residue screening. PLoS One 9:e98266. doi: 10. 1371/journal.pone.0098266

Roongsawang, N., Hase, K., Haruki, M., Imanaka, T., Morikawa, M., and Kanaya, S. (2003). Cloning and characterization of the gene cluster encoding arthrofactin synthetase from Pseudomonas sp. MIS38. Chem. Biol. 10, 869-880. doi: 10.1016/ j.chembiol.2003.09.004

Roongsawang, N., Washio, K., and Morikawa, M. (2010). Diversity of nonribosomal peptide synthetases involved in the biosynthesis of lipopeptide biosurfactants. Int. J. Mol. Sci. 12, 141-172. doi: 10.3390/ijms1201 0141

Saikia, R. R., Deka, S., Deka, M., and Banat, I. M. (2012). Isolation of biosurfactantproducing Pseudomonas aeruginosa RS29 from oil-contaminated soil and evaluation of different nitrogen sources in biosurfactant production. Ann. Microbiol. 62, 753-763. doi: 10.1007/s13213-011-0315-5

Santos, D., Rufino, R., Luna, J., Santos, V., and Sarubbo, L. (2016). Biosurfactants: multifunctional biomolecules of the 21st Century. Int. J. Mol. Sci. 17:401. doi: $10.3390 /$ ijms 17030401 
Schneider, T., Gries, K., Josten, M., Wiedemann, I., Pelzer, S., Labischinski, H., et al. (2009). The lipopeptide antibiotic Friulimicin B inhibits cell wall biosynthesis through complex formation with bactoprenol phosphate. Antimicrob. Agents Chemother. 53, 1610-1618. doi: 10.1128/AAC.01040-08

Sinnaeve, D., Michaux, C., Van hemel, J., Vandenkerckhove, J., Peys, E., Borremans, F. A. M., et al. (2009). Structure and X-ray conformation of Pseudodesmins $\mathrm{A}$ and B, two new cyclic lipodepsipeptides from Pseudomonas bacteria. Tetrahedron 65, 4173-4181. doi: 10.1016/j.tet.2009.03.045

Tabbene, O., Kalai, L., Ben Slimene, I., Karkouch, I., Elkahoui, S., Gharbi, A., et al. (2011). Anti-Candida effect of bacillomycin D-like lipopeptides from Bacillus subtilis B38: anti-Candida compounds from B. subtilis sp. B38. FEMS Microbiol. Lett. 316, 108-114. doi: 10.1111/j.1574-6968.2010.02199.x

Tagg, J. R., and McGiven, A. R. (1971). Assay system for bacteriocins. Appl. Microbiol. 21:943.

Toribio, J., Escalante, A. E., Caballero-Mellado, J., González-González, A., Zavala, S., Souza, V., et al. (2011). Characterization of a novel biosurfactant producing Pseudomonas koreensis lineage that is endemic to Cuatro Ciénegas basin. Syst. Appl. Microbiol. 34, 531-535. doi: 10.1016/j.syapm.2011.0 1.007

Vernozy-Rozand, C., Feng, P., Montet, M. P., Ray-Gueniot, S., Villard, L., Bavai, C., et al. (2000). Detection of Escherichia coli O157:H7 in heifers' faecal samples using an automated immunoconcentration system. Lett. Appl. Microbiol. 30, 217-222. doi: 10.1046/j.1472-765x.2000.00702.x

von Neubeck, M., Huptas, C., Glück, C., Krewinkel, M., Stoeckel, M., Stressler, T., et al. (2017). Pseudomonas lactis sp. nov. and Pseudomonas paralactis sp. nov., isolated from bovine raw milk. Int. J. Syst. Evol. Microbiol. 67, 1656-1664. doi: 10.1099/ijsem.0.001836

Walter, V., Syldatk, C., and Hausmann, R. (2010). Screening concepts for the isolation of biosurfactant producing microorganisms. Adv. Exp. Med. Biol. 672, 1-13. doi: 10.1007/978-1-4419-5979-9_1

Weisshoff, H., Hentschel, S., Zaspel, I., Jarling, R., Krause, E., and Pham, T. L. (2014). PPZPMs-a novel group of cyclic lipodepsipeptides produced by the Phytophthora alni associated strain Pseudomonas sp. JX090307-the missing link between the Viscosin and Amphisin Group. Nat. Prod. Commun. 9, 989-996.

Wolfe, B. E., Button, J. E., Santarelli, M., and Dutton, R. J. (2014). Cheese rind communities provide tractable systems for In Situ and In Vitro studies of microbial diversity. Cell 158, 422-433. doi: 10.1016/j.cell.2014.05.041

Wüthrich, K. (1986). NMR of Proteins and Nucleic Acids. New York, NY: Wiley.

Conflict of Interest Statement: The authors declare that the research was conducted in the absence of any commercial or financial relationships that could be construed as a potential conflict of interest.

Copyright (C) 2018 Schlusselhuber, Godard, Sebban, Bernay, Garon, Seguin, Oulyadi and Desmasures. This is an open-access article distributed under the terms of the Creative Commons Attribution License (CC BY). The use, distribution or reproduction in other forums is permitted, provided the original author(s) or licensor are credited and that the original publication in this journal is cited, in accordance with accepted academic practice. No use, distribution or reproduction is permitted which does not comply with these terms. 